\title{
Te-Bi 玻璃对晶体硅太阳能电池正银电极性能的影响
}

$$
\text { 付 明 }{ }^{1,2} \text {, 程思国 }{ }^{1,2} \text {, 王 玥 }{ }^{1,2} \text {, 周 洪 }{ }^{1,2} \text {, 范 琳 }{ }^{3}
$$

(1. 华中科技大学 光学与电子信息学院, 武汉 430074; 2. 华中科技大学 教育部信息功能材料重点实验室(B 类), 武汉 430074; 3. 武汉优乐光电科技有限公司, 武汉 430206)

摘 要: 正银浆料是晶体硅太阳能电池金属化的关键材料, 环保型浆料是正银电极的主要发展方向之一。通过正交 实验方法, 研究了不同配方和组分的 Te-Bi 玻璃对正银电极性能的影响。用 TGA-DSC 分析了 Te-Bi 玻璃和正银浆 料的热处理特性, 用 SEM 分析了 Ag-Si 界面处银微晶的分布和大小, 利用隧道电流模型分析了玻璃对正银电极性 能的影响规律。结果表明: $\mathrm{TeO}_{2}$ 含量 $45 \mathrm{wt} \%, \mathrm{Bi}_{2} \mathrm{O}_{3}$ 含量 $36 \mathrm{wt} \%$ 的 $\mathrm{Z7}$ 玻璃, 其 $T_{\mathrm{g}}$ 为 $379.07^{\circ} \mathrm{C}$, 对应的正银浆料在 $612.8^{\circ} \mathrm{C}$ 出现吸热反应，同时发生失重 $(-0.16 \%)$, 制作的多晶硅电池效率达到 $16.87 \%$, 电极的附着力达到 $4.35 \mathrm{~N}$ 。

关 键 词: 晶体硅太阳能电池; 无铅玻璃; 正银电极; 电池性能

中图分类号: TQ174 文献标识码: A

\section{Effects of Te-Bi Glass Frit on Performances of Front Silver Contacts for Crystalline Silicon Solar Cells}

\author{
FU Ming ${ }^{1,2}$, CHENG Si-Guo ${ }^{1,2}$, WANG Yue ${ }^{1,2}$, ZHOU Hong ${ }^{1,2}$, FAN Lin $^{3}$
}

\begin{abstract}
(1. School Of Optics and Electronics Information HUST, Wuhan 430074, China; 2. Ministry of Education Key Laboratory of
\end{abstract} Information Materials(B), wuhan 430074; 3. Optoelectronics Technology Co., Ltd. YL, Wuhan 430206, China)

\begin{abstract}
Front silver paste is a key material for metalization of crystalline silicon solar cells. Environmental-friendly paste is one of the main development direction for the front silver contacts. The effects of Te-Bi glass frits with different formulations and components on the performances of front silver contacts were studied by orthogonal experimental method. The heating characteristics of Te-Bi glass frit and front silver pastes were analyzed by TGA-DSC. Size and distribution of the silver microcrystalline on Ag-Si interface were observed by SEM. The influence of glass on the performances of the front silver contacts was analyzed by using tunneling current model. The results show that the transition temperature $\left(T_{\mathrm{g}}\right)$ of $\mathrm{Z7}$ glass frit composed of $45 \mathrm{wt} \% \mathrm{TeO}_{2}$ and $36 \mathrm{wt} \%$ $\mathrm{Bi}_{2} \mathrm{O}_{3}$ is $379.07^{\circ} \mathrm{C}$. The endothermic reaction of corresponding paste occurs at $612.8^{\circ} \mathrm{C}$ with $0.16 \%$ weight loss occurring at the same temperature. The efficiency of polycrystalline silicon solar cells using the corresponding front silver paste is $16.87 \%$, and adhesion of the cell is $4.35 \mathrm{~N}$.
\end{abstract}

Key words: crystalline silicon solar cells; lead-free glass frit; front silver contacts; cell performances

正银浆料是制作晶体硅太阳能电池正面电极的 关键材料, 直接影响太阳能电池的转换效率 $(\eta)$ 、串 联电阻 $\left(R_{\mathrm{s}}\right)$ 、开路电压 $\left(V_{\mathrm{oc}}\right)$ 等性能。正银浆一般由银 粉、玻璃料和有机载体等组成, 其中玻璃粉作为无
机粘接剂提高银厚膜电极的附着力, 腐蚀晶体硅表 面的 $\mathrm{SiN}_{x}$ 减反膜，以及溶解 $\mathrm{Ag}$ 并输送到 $\mathrm{Ag}-\mathrm{Si}$ 界 面, 保证 $\mathrm{Ag}$ 与 $\mathrm{Si}$ 形成欧姆接触 ${ }^{[1-2]}$ 。

目前，普遍使用的正银浆料采用的玻璃料主要 
是 $\mathrm{Pb}$ 玻璃, 它具有玻璃熔点低、高温熔化时流动性 好, 对硅表面润湿性好, 以及电性能稳定可靠等特 点, 但其对环境不友好, 因此正银浆料的无铅化, 即环保型浆料的研究是太阳能电池金属化技术的研 究热点之一。用于正银浆料的无铅玻璃体系主要有: $\mathrm{Bi}_{2} \mathrm{O}_{3}-\mathrm{SiO}_{2}-\mathrm{Al}_{2} \mathrm{O}_{3}$ 系、 $\mathrm{ZnO}-\mathrm{B}_{2} \mathrm{O}_{3}-\mathrm{SiO}_{2}$ 系、 $\mathrm{V}_{2} \mathrm{O}_{5}-$ $\mathrm{BaO}-\mathrm{ZnO}$ 系和 $\mathrm{TeO}_{2}-\mathrm{Bi}_{2} \mathrm{O}_{3}$ 系等。 $\mathrm{Kim}$ 等 ${ }^{[3]}$ 研究了 $\mathrm{Bi}-\mathrm{Si}-\mathrm{Al}-\mathrm{Zn}-\mathrm{B}$ 无铅玻璃料, 研究表明, 随着玻璃粉 的软化温度和液相温度的升高, 电池的填充因子和 光电转化效率都将增大, 并制作了光电转换效率达 $15.02 \%$ 的电池。Jaap 等 ${ }^{[4]}$ 指出正银玻璃料中替代铅 的物质应具有如下性能: 1)金属氧化物能被减反层 $\mathrm{SiN}_{x}$ 和 $\mathrm{Si}$ 还原; 2)能与 $\mathrm{Ag}$ 形成合金; 3)玻璃料对 $\mathrm{Si}$ 的刻蚀速度比对减反层的刻蚀速度小, 并依照此思 路制备了电池效率达 $16.6 \%$ 的无铅银浆。

$\mathrm{TeO}_{2}$ 的熔点低 $\left(733^{\circ} \mathrm{C}\right)$, 可以降低玻璃的转变温度 $\left(T_{\mathrm{g}}\right)$, 并且 $\mathrm{TeO}_{2}-\mathrm{Bi}_{2} \mathrm{O}_{3}$ 玻璃具有与 $\mathrm{TeO}_{2}-\mathrm{PbO}$ 玻璃相似 的特性, 是无铅正银浆料的优选玻璃之一。本工作针对 $\mathrm{TeO}_{2}-\mathrm{Bi}_{2} \mathrm{O}_{3}$ 系玻璃的主要影响因素, 利用正交试验方 法, 研究了不同玻璃组分对正银电极性能的影响。

\section{1 实验方法}

\section{1 玻璃料的制备}

根据正交实验原理, 对于 $\mathrm{TeO}_{2}-\mathrm{Bi}_{2} \mathrm{O}_{3}$ 系玻璃, 考虑 $\mathrm{TeO}_{2} 、 \mathrm{Bi}_{2} \mathrm{O}_{3} 、 \mathrm{SiO}_{2} 、 \mathrm{~L}_{2} \mathrm{O}$ 和 $\mathrm{MO}$ 等 5 个因素, 每 个因素选 4 个水平, 具体如表 1 所示, 表中各水平为 玻璃配方中的重量百分比 $(\mathrm{wt} \%) 。 \mathrm{~L}_{2} \mathrm{O}$ 由碱金属氧化 物 $\mathrm{Li}_{2} \mathrm{O} 、 \mathrm{Na}_{2} \mathrm{O}$ 按一定比例组成; $\mathrm{MO}$ 由玻璃中间体 氧化物 $\mathrm{Al}_{2} \mathrm{O}_{3} 、 \mathrm{ZnO} 、 \mathrm{CaO} 、 \mathrm{SrO}$ 等按一定比例组成。 依照正交实验的原理, 设计出 4 水平、5 因素的标准 正交表 $\mathbf{L}_{16}\left(\mathbf{4}^{5}\right)$, 共制备 16 个玻璃样品, 分别编号为 Z1 Z16, 样品具体配方如表 2 所示。表中所用氧化 物原料均为分析纯。按照表 2 配方称料, 将氧化物 原料混合均匀。玻璃的烧结工艺为: 高温 $1100^{\circ} \mathrm{C}$, 保温 $1 \mathrm{~h}$ 。玻璃经高温淬火后球磨 $2 \mathrm{~h}$, 烘干后得到 $D_{50}$ 粉粒径小于 $3 \mu \mathrm{m}$ 的玻璃粉。

表 1 正交实验水平与因素

Table 1 Orthogonal experimental levels and factors

\begin{tabular}{cccccc}
\hline \multirow{2}{*}{ No. } & 1 & 2 & 3 & 4 & 5 \\
\cline { 2 - 6 } & $\mathrm{TeO}_{2}$ & $\mathrm{Bi}_{2} \mathrm{O}_{3}$ & $\mathrm{SiO}_{2}$ & $\mathrm{~L}_{2} \mathrm{O}$ & $\mathrm{MO}$ \\
\hline 1 & 40 & 28 & 0 & 0 & 3 \\
2 & 45 & 32 & 2 & 2 & 6 \\
3 & 50 & 36 & 4 & 4 & 9 \\
4 & 55 & 40 & 6 & 6 & 12 \\
\hline
\end{tabular}

表 2 正交试验玻璃配方表

Table 2 Glass recipe table of orthogonal experiment

\begin{tabular}{cccccc}
\hline & \multicolumn{5}{c}{ Glass recipe/wt\% } \\
\cline { 2 - 6 } No. & $\mathrm{TeO}_{2}$ & $\mathrm{Bi}_{2} \mathrm{O}_{3}$ & $\mathrm{SiO}_{2}$ & $\mathrm{~L}_{2} \mathrm{O}$ & $\mathrm{MO}$ \\
\hline $\mathrm{Z} 1$ & 40 & 28 & 0 & 0 & 3 \\
$\mathrm{Z} 2$ & 40 & 32 & 2 & 2 & 6 \\
$\mathrm{Z} 3$ & 40 & 36 & 4 & 4 & 9 \\
$\mathrm{Z} 4$ & 40 & 40 & 6 & 6 & 12 \\
$\mathrm{Z} 5$ & 45 & 28 & 4 & 6 & 6 \\
$\mathrm{Z} 6$ & 45 & 32 & 6 & 4 & 3 \\
$\mathrm{Z} 7$ & 45 & 36 & 0 & 2 & 12 \\
$\mathrm{Z} 8$ & 45 & 40 & 2 & 0 & 9 \\
$\mathrm{Z} 9$ & 50 & 28 & 6 & 2 & 9 \\
$\mathrm{Z} 10$ & 50 & 32 & 4 & 0 & 12 \\
$\mathrm{Z} 11$ & 50 & 36 & 2 & 6 & 3 \\
$\mathrm{Z} 12$ & 50 & 40 & 0 & 4 & 6 \\
$\mathrm{Z} 13$ & 55 & 28 & 2 & 4 & 12 \\
$\mathrm{Z} 14$ & 55 & 32 & 0 & 6 & 9 \\
$\mathrm{Z} 15$ & 55 & 36 & 6 & 0 & 6 \\
$\mathrm{Z} 16$ & 55 & 40 & 4 & 2 & 3 \\
\hline & & & & & \\
\hline
\end{tabular}

\section{2 正银浆料及正银电极的制备}

正银浆料配比为: 玻璃 $2 \mathrm{wt} \%$, 银粉 $88 \mathrm{wt} \%$ 和有 机载体 $10 \mathrm{wt} \%$ 。浆料经三辊研磨工艺制得, 浆料细度 小于 $10 \mu \mathrm{m}$ 。

硅片选用多晶已镀膜蓝片, 方阻为: $80 \Omega /$, 尺 寸为 6 英寸硅片的 $1 / 9$ 大小, 印刷网版为 360 目, 栅 线宽度为 $80 \mu \mathrm{m}$, 每个样品印刷 6 片。采用 9 温区 红外隧道烧结炉进行电池烧结, 烧结工艺为: 传送 速度设为 $6.1 \mathrm{~m} / \mathrm{min}$, 各温区温度为: $300^{\circ} \mathrm{C} 、 310^{\circ} \mathrm{C}$ 、 $320^{\circ} \mathrm{C} 、 480^{\circ} \mathrm{C} 、 520^{\circ} \mathrm{C} 、 560^{\circ} \mathrm{C} 、 600^{\circ} \mathrm{C} 、 810^{\circ} \mathrm{C} 、 900^{\circ} \mathrm{C}$ 。 同时，采用目前市面普遍使用的一款有铅浆料制作 电池片, 进行性能对比测试。

\section{3 性能表征}

用电池综合参数测试仪(GSCT-B)测试样品的光 电性能, 测试条件为: 温度 $25^{\circ} \mathrm{C}$, 光强为 $100 \mathrm{~mW} / \mathrm{cm}^{2}$, 每种样品测试 6 片, 取平均值作为试验结果。用拉 力计测试电极附着力, 测试时先焊接焊带, 反向 $180^{\circ}$ 拉脱焊带, 测试拉脱力即为电极附着力。用 TGA-DSC(METTLER TOLEDO, TGA/DSC-1)分析 玻璃和浆料的热处理特性; 用 SEM(TESCAN, VEGA-3-SBH) 分析硅表面及断面的银微晶大小和 分布; 用 XRD(XRD-7000, Shimadizu, Kyoto, Japan) 测试玻璃的晶体特性。 


\section{2 结果与讨论}

\section{1 玻璃组分对电池片性能的影响}

不同玻璃正银浆料制作的电池片电性能如表 3 所示, 从表中可以看出, Z7 样品的电池效率最高, 达 $16.87 \%$, 与有铅浆料电池的效率基本接近, 对比 的有铅浆料 Z 电池效率为 $17.07 \%$, 两者的电池效率 差距为 $0.2 \%$ 。该对比浆料是普遍使用的一款含铅正 银浆，通过相同的印刷和烧结工艺条件制作。Z1、 Z6、Z15 和 Z16 样品的电池效率都低于 $10 \%$, 其他 样品电池的效率处于中间水平。电极的附着力也差 别很大, 附着力较好的样品 Z3、Z4、Z7 和 Z8 都大 于 $4 \mathrm{~N}$, 其余样品附着力较差, $Z 15$ 仅为 $0.35 \mathrm{~N}$ 。电池 效率与串联电阻 $R_{\mathrm{s}}$ 的关系很大, $R_{\mathrm{s}}$ 小的电池, 其转换 效率也较高, Z7 样品的 $R_{\mathrm{s}}$ 最小, 只有 $77.14 \mathrm{~m} \Omega$ 。

图 1 为正银电极结构示意图, 正银电极通过烧 结而形成。在烧结期间, 玻璃和无机添加物有助于 腐蚀穿透减反层(ARC layer), 并且可以在银和晶体 硅层之间形成稳定的机械力和电力传导接触 ${ }^{[5]}$ 。在 高温烧结过程中, 玻璃料粉的粘度急剧减小, 液态 部分迅速浸润银颗粒并腐蚀 $\mathrm{SiN}_{x}$ 层。银颗粒被溶解 在液态玻璃中并生长进入晶体硅, 最终在硅发射极 表面形成银微晶粒。因此, 氮化硅层通过与玻璃料 发生氧化还原反应而发生腐蚀:

$2 \mathrm{Bi}_{2} \mathrm{O}_{3}$ (glass) $+3 \mathrm{SiN}_{x}(\mathrm{~s}) \rightarrow 4 \mathrm{Bi}(\mathrm{l})+3 \mathrm{SiO}_{2}$ (in glass) +

$$
3 x / 2 \mathrm{~N}_{2}(\mathrm{~g}) \uparrow
$$

表 3 正交试验电池片性能

\section{Table 3 Cell performances of orthogonal experiments}

\begin{tabular}{cccccc}
\hline $\mathrm{No}$ & $\eta / \%$ & $V_{\mathrm{oc}} / \mathrm{V}$ & $I_{\mathrm{sc}} / \mathrm{A}$ & $R_{\mathrm{s}} / \mathrm{m} \Omega$ & Adhesion/N \\
\hline $\mathrm{Z}$ & 17.07 & 0.622 & 1.004 & 68.26 & 4.04 \\
$\mathrm{Z} 1$ & 7.13 & 0.617 & 0.847 & 434.12 & 2.35 \\
$\mathrm{Z} 2$ & 12.85 & 0.620 & 0.958 & 110.97 & 2.60 \\
$\mathrm{Z} 3$ & 13.98 & 0.615 & 1.049 & 106.51 & 4.40 \\
$\mathrm{Z} 4$ & 12.01 & 0.619 & 1.059 & 151.55 & 4.15 \\
$\mathrm{Z} 5$ & 11.12 & 0.612 & 1.009 & 171.31 & 1.85 \\
$\mathrm{Z6}$ & 5.61 & 0.614 & 0.996 & 580.61 & 1.40 \\
$\mathrm{Z7}$ & 16.87 & 0.621 & 1.009 & 71.14 & 4.35 \\
$\mathrm{Z} 8$ & 13.21 & 0.621 & 0.959 & 120.16 & 4.60 \\
$\mathrm{Z} 9$ & 10.50 & 0.616 & 0.998 & 180.06 & 1.70 \\
$\mathrm{Z} 10$ & 13.15 & 0.621 & 1.039 & 181.08 & 2.75 \\
$\mathrm{Z} 11$ & 11.75 & 0.619 & 0.998 & 148.39 & 1.25 \\
$\mathrm{Z} 12$ & 13.98 & 0.616 & 1.087 & 86.99 & 3.20 \\
$\mathrm{Z} 13$ & 11.50 & 0.611 & 0.974 & 229.12 & 2.30 \\
$\mathrm{Z} 14$ & 10.35 & 0.619 & 0.986 & 206.66 & 1.95 \\
$\mathrm{Z} 15$ & 8.78 & 0.617 & 0.918 & 564,57 & 0.35 \\
$\mathrm{Z} 16$ & 7.70 & 0.619 & 0.977 & 598.99 & 1.50 \\
\hline & & & & &
\end{tabular}

反应后生成了 $\mathrm{Bi}$ 和 $\mathrm{SiO}_{2}$ 的沉淀物。因此, 作为 媒介的玻璃很大程度上决定着金属化接触结构和银 电极的烧结质量 ${ }^{[6]}$ 。

正银电极的电流传导模型如图 2 所示。在正银 电极上，电流的传输途径一般有三种 $\left.{ }^{[7]}: 1\right)$ 在银微晶 和银块之间孤立点上的直接接触; 2)隧穿通过极薄 的玻璃区域；3)隧穿通过玻璃层中不连续的银微晶 粒，穿过玻璃层传导。第 2 和 3 两种传导模式都与 玻璃层有关，因此玻璃中银微晶的大小和数量对于 电流传导的影响很大。

不同配方和组分的玻璃的转变温度 $\left(T_{\mathrm{g}}\right)$ 和高温 熔化特性是不同的，不同玻璃对于 $\mathrm{SiN}_{x}$ 的腐蚀性和 金属银的溶解能力也不相同，因此不同玻璃对于正 银电极的烧结特性有很大影响。随着 $\mathrm{TeO}_{2}$ 含量的增 加, 玻璃的 $T_{\mathrm{g}}$ 会降低, 玻璃高温熔化时的粘度也会 下降。随着玻璃中 $\mathrm{Bi}_{2} \mathrm{O}_{3}$ 含量的增加, 玻璃的 $T_{\mathrm{g}}$ 会 上升, 玻璃的粘度也会增加。 $\mathrm{SiO}_{2}$ 也是一种玻璃形 成剂，其含量增加时，玻璃的 $T_{\mathrm{g}}$ 也会上升。一价金 属氧化物 $\mathrm{L}_{2} \mathrm{O}$ 可以降低玻璃的熔点和粘度, 网络中 间体氧化物 $\mathrm{MO}$ 可以调整玻璃的熔点和高温粘度。 $\mathrm{Z} 7$ 样品中 $\mathrm{TeO}_{2}$ 含量为 $45 \mathrm{wt} \%, \mathrm{Bi}_{2} \mathrm{O}_{3}$ 含量为 $36 \mathrm{wt} \%$, 加上合适的其他组分含量, 使玻璃的特性与正银的 烧结工艺匹配, 电池表现出较高的转换效率。

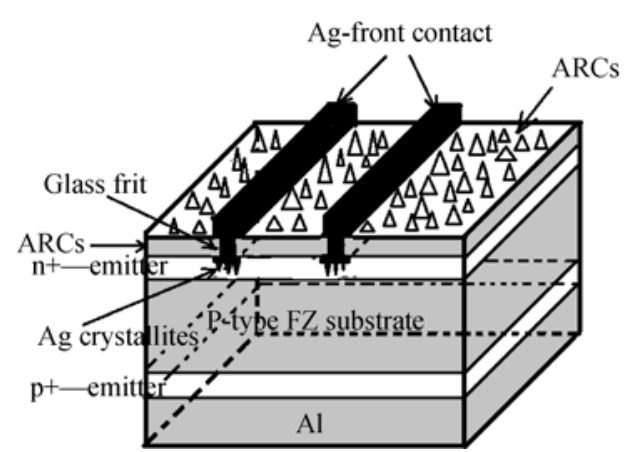

图 1 正银电极结构示意图

Fig. 1 Structure of the front-contact silver electrode

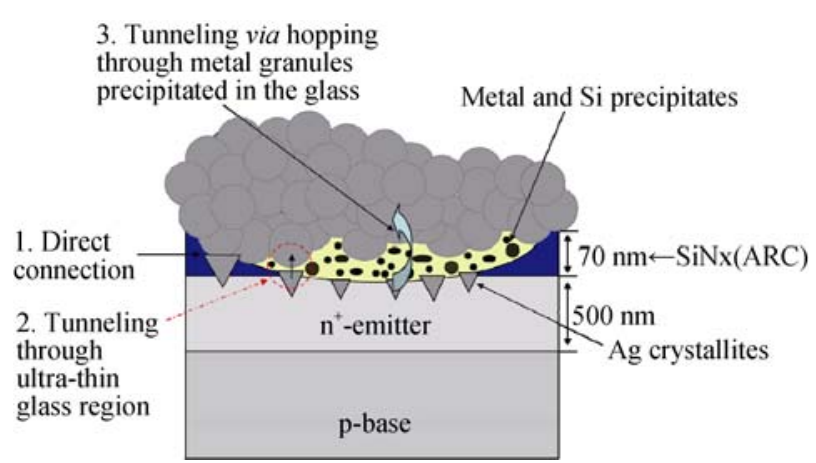

图 2 正银电流传导模型图

Fig. 2 Models of current transport in front contact silver electrode 


\section{2 玻璃对正银浆料热处理特性的影响}

根据电池的转换效率和正交试验的玻璃影响因 素分布, 从 16 组样品选出 4 组具有代表性的样品进 行玻璃和浆料的差热分析, 以研究玻璃料对正银浆 料烧结特性的影响。试验选择了电池效率最高的 Z7, 效率水平中上的 $\mathrm{Z} 3$ 和 $\mathrm{Z} 10$, 及效率接近最低的 $Z 16$ 。由于附着力指标是一个范围, 只要大于 $3 \mathrm{~N}$ 即 可, 不作为选取代表样品的主要依据。

4 组玻璃样品 Z3、Z7、Z10 和 Z16 的 TGA-DSC 曲线如图 3 可所示(差热分析的试验条件为: 温度范围 $25^{\circ} \mathrm{C} \sim 750^{\circ} \mathrm{C}$, 升温速率 $10^{\circ} \mathrm{C} / \mathrm{min}$, 测试时通空气)。从 图 3 可看出, $\mathrm{Z3}$ 玻璃在温度升到 $377.14^{\circ} \mathrm{C}$ 时, 出现了 一个吸热峰, 即 Z3 玻璃料的 $T_{\mathrm{g}}$ 为 $377.14^{\circ} \mathrm{C}$ 。相应的 $\mathrm{Z7} 、 \mathrm{Z10} 、 \mathrm{Z16}$ 玻璃料的 $T_{\mathrm{g}}$ 分别为 $379.07^{\circ} \mathrm{C} 、 403.30^{\circ} \mathrm{C}$ 、 $394.72^{\circ} \mathrm{C}$ 。从表 3 可以看出, $T_{\mathrm{g}}$ 较低的 $\mathrm{Z} 3$ 和 $\mathrm{Z} 7$ 玻璃 比 $T_{\mathrm{g}}$ 较高的 $\mathrm{Z} 10$ 和 $\mathrm{Z} 16$ 玻璃的电池片的效率要高。 从图 3 可的 TGA 曲线可看出, 四种玻璃在加热过程中, 高温下都有一个逐渐增重的过程, 增重量在 $0.1 \% \sim 0.3 \%$ 范围, 表明玻璃在加热过程中有氧溶入, 这将对于玻璃中银的溶入和析出有较大影响。

4 组玻璃 Z3、Z7、 Z10 和 Z16 制作的正银浆料 的 TGA-DSC 曲线如图 4 所示。从图 4 可看出, 当 温度升至 $400^{\circ} \mathrm{C}$ 以上, 随着温度的升高, 正银浆料
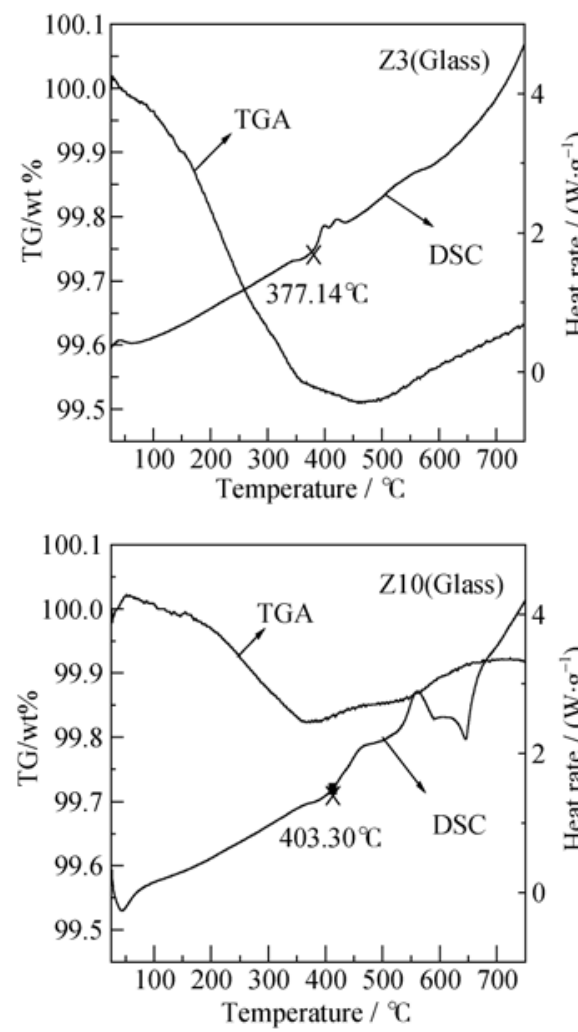

产生了增重现象。这是由于在加热过程中，玻璃逐 渐变成液相, 部分银粉被液相玻璃浸润, 溶解在玻 璃中的部分银原子与周围环境中的氧气发生反应:

$$
4 \mathrm{Ag}(\mathrm{s})+\mathrm{O}_{2}(\mathrm{~g}) \rightarrow 2 \mathrm{Ag}_{2} \mathrm{O} \text { (in glass) }
$$

玻璃中的 $\mathrm{Ag}_{2} \mathrm{O}$ 会分解为银离子:

$2 \mathrm{Ag}_{2} \mathrm{O}$ (in glass) $\rightarrow 4 \mathrm{Ag}^{+}$(in glass) $+2 \mathrm{O}^{-2}$ (in glass) (3) 另外, 样品在 $610^{\circ} \mathrm{C}$ 左右都有一个吸热峰, 并 伴随有 $0.1 \%$ 左右的小幅度失重，对应玻璃中的银离 子转变为单质银, 并放出 $\mathrm{O}_{2}$ 。

当电池片烧结时, 溶入玻璃中的银离子随着玻 璃的流动逐步扩散到 $\mathrm{Si}$ 发射结表面与 $\mathrm{Si}$ 反应，腐蚀 硅基体 ${ }^{[8]}$, 即发生如下反应:

$4 \mathrm{Ag}^{+}$(in glass) $+2 \mathrm{O}^{2-}$ (in glass) $+\mathrm{Si}(\mathrm{s}) \rightarrow 4 \mathrm{Ag}($ in glass $)+$

$$
\mathrm{SiO}_{2} \text { (in glass) }
$$

最后晶体银沉淀在玻璃中或沉淀在银和硅的界面上, 生成银微晶。

从上述分析可知, 浆料加热过程中 $610^{\circ} \mathrm{C}$ 左右 的吸热失重反应对于玻璃层中银微晶的形成有直接 影响, Z7 样品的失重最大 $(-0.16 \%)$, 对银微晶的形 成有利, 这与样品的组分有关, 从表 2 可知, $\mathrm{Z} 7$ 样品 $\mathrm{TeO}_{2}$ 含量为 $45 \%$, 并且不含 $\mathrm{SiO}_{2}$ 。

为了解玻璃的形成状态, 对 Z3、Z7、Z10 和 Z16 玻璃进行了 XRD 分析, 结果如图 5 所示。从图 5 可
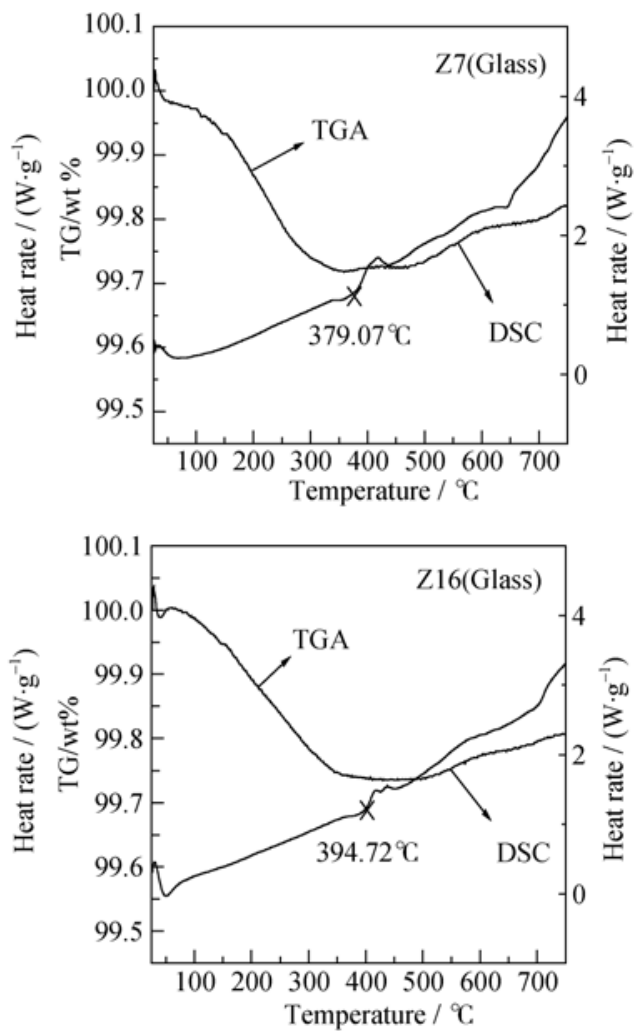

图 $3 \mathrm{Z} 3 、 \mathrm{Z} 7 、 \mathrm{Z} 10$ 和 Z16 玻璃的差热曲线

Fig. 3 DTA curves of lead-free glass frits of Z3, Z7, Z10 and Z16 

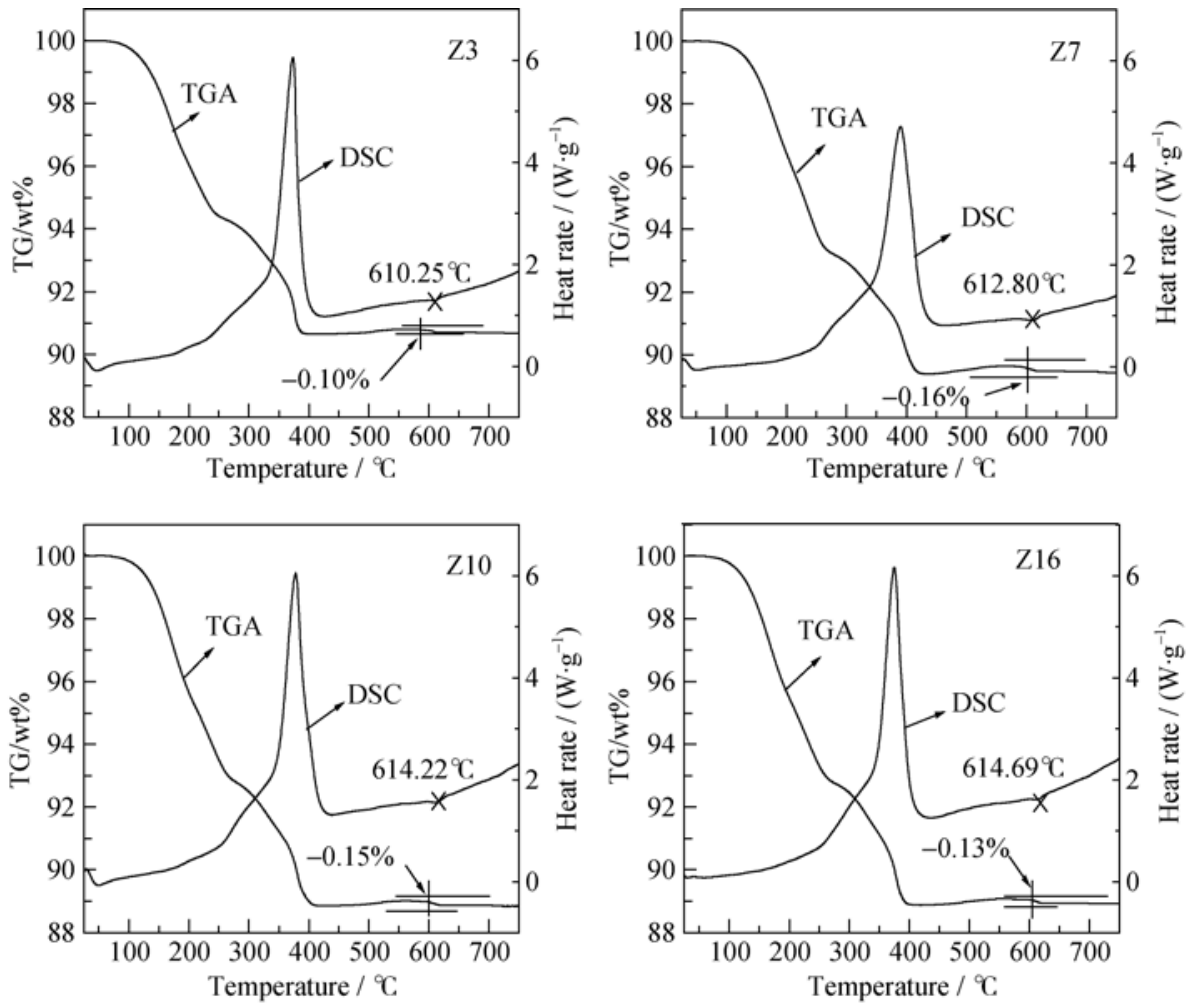

图 4 Z3、Z7、Z10 和 Z16 正银浆差热曲线

Fig. 4 DTA curves of front-contact silver paste of Z3, Z7, Z10 and Z16

以发现四组玻璃的晶型结构很相似, 均没有尖锐的 晶体衍射峰, 都呈现出完美的玻璃态, 表明 $\mathrm{TeO}_{2}$ 含 量 $40 \mathrm{wt} \% \sim 55 \mathrm{wt} \%, \mathrm{Bi}_{2} \mathrm{O}_{3}$ 含量 $28 \mathrm{wt} \% \sim 40 \mathrm{wt} \%$ 都能形 成很好的 $\mathrm{Te}-\mathrm{Bi}$ 玻璃态。

\section{3 玻璃料对电极微观结构的影响}

对制备的 16 组样品的银电极进行电镜(SEM) 观察。通过电镜分析, 16 组样品的正银电极在电极

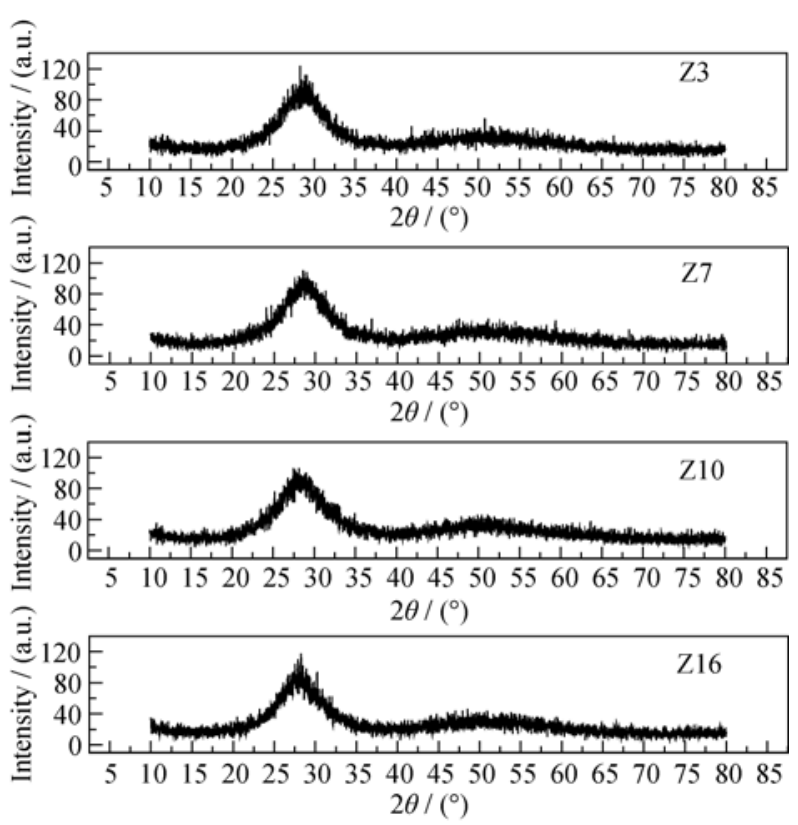

图 5 玻璃样品的 XRD 图谱

Fig. 5 XRD patterns of the glass frit
边缘处的硅表面上都有银微晶析出，其中 Z3、Z7、 Z10 和 Z16 组样品银微晶析出情况如图 6 所示。

玻璃的组分不同会引起玻璃的 $T_{\mathrm{g}}$ 及高温液体 粘度等特性的变化, 从而引起玻璃中溶入和析出银 量的变化, 导致不同正银电极银微晶的大小和数量 不同。从图 6 可看出, $\mathrm{Z7}$ 样品的银微晶大小适中, 银 微晶数量较多; Z3 和 Z10 样品的银微晶比较细小,
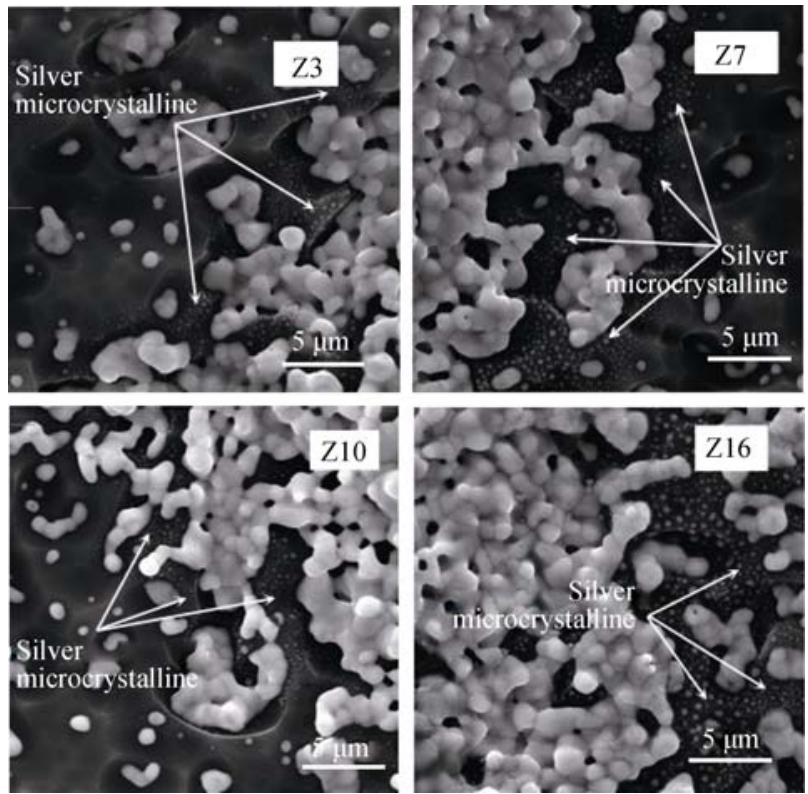

图 6 正银栅线电极银微晶的大小和分布

Fig. 6 Size and distribution of Ag crystallites in front-contact silver grid electrode 
数量也较少; Z16样品的银微晶数量较多, 但银微晶 的尺寸较大, 最大的银微晶达到了 $0.3 \mu \mathrm{m}$ 以上。根 据前述太阳能电池正银电极的电流传导模型, 当银 微晶的尺寸大小适中、数量较多、分布均匀时, 电 极的电流传导性较好 ${ }^{[9]}$, 如 Z7 的银微晶分布。银微 晶太大容易穿透电池硅片的发射结, 破坏电池的 PN 结结构, 如 Z16 样品的银微晶情况。银微晶的数 量和大小都不够, 也会影响电流的传导, 如 Z3 和 Z10 样品的银微晶情况。

图 7 可是 Z7 和 Z16 正银电极的断面 SEM 照片。 从图 7 可看出, 在厚膜银层和硅的接触面有细小的银 微晶出现, 由于采用的是多晶硅片, 硅表面有明显的 不规则凹坑, 银和硅之间存在一定的空隙。对于 $\mathrm{Z7}$ 样品, 银微晶的尺寸较小, 一般在 $0.1 \sim 0.3 \mu \mathrm{m}$; 对于 Z16 样品, 银微晶的尺寸较大, 一般在 $0.2 \sim 0.4 \mu \mathrm{m}$; 银 微晶较大时容易破坏电池的发射结, 高方阻电池的 结深一般小于 $0.3 \mu \mathrm{m}^{[10]}$, 这也正是因为 $\mathrm{Z7}$ 的电池 转换效率明显高于 Z16。

由于正银电极是金属银与 $\mathrm{n}-\mathrm{Si}$ 接触, 接触区为 重掺杂的 $\mathrm{n}$ 型发射区, 银与 $\mathrm{n}-\mathrm{Si}$ 的界面势垒很小, 正银电极与电池表面的接触电阻主要取决于银与硅 表面的接触程度。当电极中有较多的玻璃层时, 正 银电极的电流传导为隧道电流模型(图 2)。玻璃对电 池效率的影响主要是通过对接触电阻的影响产生的, 接触电阻小的电池，其转换效率更高。
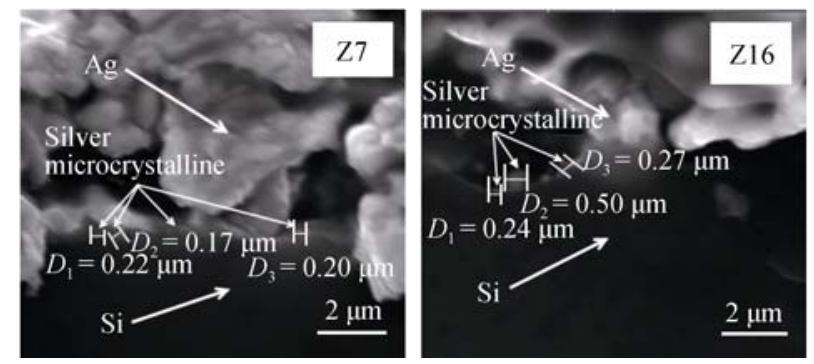

图 $7 \mathrm{Z7}$ 和 Z16 正银电极的断面 SEM 照片

Fig.7 Cross-sectional SEM images of front contacts of $\mathrm{Z7}$ and Z16

\section{3 结论}

1) 通过正交实验, 确定了 $\mathrm{Te}-\mathrm{Bi}$ 玻璃的基本配 方和组成，当 $\mathrm{TeO}_{2}$ 含量 $45 \mathrm{wt} \% 、 \mathrm{Bi}_{2} \mathrm{O}_{3}$ 含量 $36 \mathrm{wt} \%$ 、 碱金属氧化物 $\mathrm{L}_{2} \mathrm{O}$ 含量 $2 \mathrm{wt} \%$ 、中间体氧化物 $\mathrm{MO}$ 含量 $12 \mathrm{wt} \%$ 时, 玻璃的性能最优, 制作的多晶硅太 阳能电池的效率达到 $16.87 \%$, 电极的附着力达到 $4.35 \mathrm{~N}$ 。电池性能基本接近铅正银的水平。

2) 玻璃的转变温度 $\left(T_{\mathrm{g}}\right)$ 、高温粘度、腐蚀性等
对正银浆料的烧结有直接影响。 $\mathrm{Z7}$ 玻璃的 $T_{\mathrm{g}}$ 为 $379.07^{\circ} \mathrm{C}$, 对应的正银浆料在 $612.8^{\circ} \mathrm{C}$ 出现吸热反应 并有较大失重 $(-0.16 \%)$, 有利于减反射膜的腐蚀和 银微晶的形成。 $\mathrm{Z} 3$ 玻璃的 $T_{\mathrm{g}}$ 为 $377.14^{\circ} \mathrm{C}$, 浆料对应 的失重较小 $(-0.10 \%)$, 玻璃对减反射膜的腐蚀和银 微晶的形成效果较差。

3) 不同玻璃对银微晶的形成有很大影响。Z7 玻璃正银电极的银微晶数量较多, 尺寸小于 $0.3 \mu \mathrm{m}$, 分布较均匀, 有利于 $\mathrm{Ag}-\mathrm{Si}$ 导电通道的形成, 降低 电池的串联电阻，提高转换效率。Z16 玻璃正银的 银微晶数量也较多, 但粒径较大 (达 $0.5 \mu \mathrm{m}$ ), 分布 不均匀, 导致电池效率很低。

4) XRD 分析表明, $\mathrm{TeO}_{2}$ 含量 $40 \mathrm{wt} \% \sim 55 \mathrm{wt} \%$, $\mathrm{Bi}_{2} \mathrm{O}_{3}$ 含量 $28 \mathrm{wt} \% \sim 40 \mathrm{wt} \%$ 的配方都能形成很好的 $\mathrm{Te}-\mathrm{Bi}$ 玻璃态。

\section{参考文献:}

[1] HöRTEIS M, GUTBERLET T, RELLER A, et al. High-temperature contact formation on n-type silicon: basic reactions and contact model for seed-layer contacts. Adv. Funct. Mater., 2010, A20(3): $476-484$.

[2] KIM J H, KOO H Y, KO Y N, et al. Characteristics of Bi-based glass frit having similar mean size and morphology to those of silver powders at high firing temperatures. Journal of Alloys and Compounds, 2010, 497: 259-266.

[3] KIM DONGSUN, HWANG SEONGJIN, KIM HYUNGSUN. Effect of the thermal properties of frits on the electrical properties of screen-printed silicon solar cells. Journal of the Korean Physical Society, 2009, 55(3): 1046-1050.

[4] JAAP HOORNSTRA, GUNNAR SCHUBERT, KEES BROEK. Lead Free Metallisation Pastefor Crystalline Silicon Solar Cells: from Model to Results. 31st IEEE Photovoltaic Specialists Conference, 2005

[5] HILALI M M, NAKAYASHIK K, KHADIKAR C. Effect of Ag particle size in thick-film Ag paste on the electrical and physical properties of screen printed contacts and silicon solar cells. $J$. Electro-chem. Soc., 2006, 153(1): A5-A11.

[6] CHE Q D, YANG H X, LU L, et al. A new environmental friendly silver front contact paste for crystalline silicon solar cells. Journal of Alloys and Compounds, 2013, 549 : 221-225.

[7] MOHAMED M, SRIDHARAN H S, KHADILKAR C, et al. Effect of glass frit chemistry on the physical and electrical properties of thick-film Ag contacts for silicon solar cells. Electro. Mater, 2006, 35(11): 2041-2047.

[8] TSAI JUNG-TING, LIN SHUN-TIAN. Silver powder effectiveness and mechanism of silver paste on silicon solar cells. Journal of Alloys and Compounds, 2013, 548: 105-109.

[9] SCHUBERT G, HUSTER F, FATH P. Physical understanding of printed thick-film front contacts of crystalline Si solar cells-review of existing models and recent developments. Solar Energy Mater Solar Cells, 2006, 90: 3399-3406.

[10] ZHOU JUE-HUI, XU NUO-XIN, YANG HUI, et al. Effect of Ag powder and glass frit in Ag paste on front contract of silicon solar cells. Procedia Engineering, 2014, 94(6): 1-5. 